\title{
Developing a Prototype Earthquake Early Warning System in the Beijing Capital Region
}

\section{Hanshu Peng, ${ }^{1}$ Zhongliang $\mathbf{W u},{ }^{1}$ Yih-Min $\mathbf{W u},{ }^{2}$ Shuming $\mathrm{Yu}{ }^{3}$ Dongning Zhang, ${ }^{1}$ and Wenhui Huang ${ }^{4}$}

\section{INTRODUCTION}

The Beijing capital region $\left(36^{\circ} \mathrm{N}-42^{\circ} \mathrm{N}, 113.5^{\circ} \mathrm{E}-120^{\circ} \mathrm{E}\right)$ is located in northern China and includes Beijing City, Tianjin City, and Hebei Province. This region of critical economic and cultural importance is threatened by large earthquakes. Historical earthquake records show that this region has been struck by many strong-to-great earthquakes (see Figure 1), with magnitudes up to $\mathbf{M} 8$ (the 1679 Sanhe-Pinggu earthquake). In the 20th century, the 1976 M 7.8 Tangshan earthquake caused more than 240,000 fatalities and uncountable economic losses. Developing an earthquake early warning system (EEWS) in this region is therefore of great importance and necessity. This necessity was dramatically highlighted by the disastrous Wenchuan earthquake in 2008. After the Wenchuan earthquake, a news media report that Japanese seismologists could "predict" an earthquake several seconds before its occurrence caused a lot of discussion in China. This was actually a misunderstanding of the EEWS performance during the IwateMiyagi Nairiku earthquake on 14 June 2008, about one month after the Wenchuan earthquake, but the importance of EEWS in earthquake disaster mitigation has become more and more evident. Accordingly, the China Earthquake Administration (CEA) was motivated to configure a nationwide EEWS.

EEW systems have recently been developed in many countries and regions, such as Japan (Nakamura 1988, 1996, 2004; Horiuchi et al. 2005; Nakamura and Saita 2007; Hoshiba et al. 2008; Brown et al. 2009; Kamigaichi et al. 2009), southern California (Allen and Kanamori 2003; Wu et al. 2007; Böse et al. 2008; Allen, Brown et al. 2009; Böse et al. 2009; Cua et al. 2009; Köhler et al. 2009), Mexico (Espinosa-Aranda et al. 1995; Goltz and Flores 1997; Espinosa-Aranda et al. 2009; Suárez et al. 2009), Taiwan (Wu and Teng 2002; Hsiao et al. 2009), Turkey (Erdik et al. 2003; Alcik et al. 2009; Fleming et al. 2009), Romania (Wenzel et al. 1999; Ionescu et al. 2007), and Italy (Zollo et al. 2006; Weber et al. 2007; Olivieri et al. 2008; Zollo et al. 2009). Studies of the properties of seismic

1. Institute of Geophysics, China Earthquake Administration, Beijing

2. Department of Geosciences, National Taiwan University, Taipei

3. Department of Earthquake Monitoring and Prediction, China Earthquake Administration, Beijing

4. Earthquake Administration of Guangdong Province, Guangzhou waves and strong ground motion have provided scientific grounds for the implementation of EEWS (Nakamura 1988; Espinosa-Aranda et al. 1995; Allen and Kanamori 2003; Kamigaichi 2004; Kanamori 2005; Wu and Kanamori 2005a, 2005b; Wu et al. 2006; Zollo et al. 2006; Böse et al. 2007; Cua and Heaton 2007; Wu et al. 2007; Wurman et al. 2007; Yamada et al. 2007; Böse et al. 2008; Shieh et al. 2008; Wu and Kanamori 2008a, 2008b; Yamada and Heaton 2008; Köhler $e t$ al. 2009; Satriano et al. 2011). The Beijing capital region (BCR) is a new member of the EEW family (Allen, Gasparini et al. 2009). The region has transitioned from testing mode to testing operation mode and has provided an internal prototype of the early warning service since February 2010. The performance of the system has been evaluated over a seven-month period, from 1 February 2010 to 31 August 2010. This evaluation provides useful information for the operation and optimization of the EEWS. This information is useful not only for other places in continental China but also for similar continental regions with widely scattered earthquake activities that are not as frequent as those in the plate boundary regions but include some rare earthquakes that are quite large and destructive.

\section{SYSTEM CONSTRUCTION}

The construction of the EEW system for the BCR was conducted jointly by the Institute of Geophysics (IGP) at the China Earthquake Administration (CEA) and the Department of Geosciences, National Taiwan University, before the 2008 Wenchuan earthquake. It was supported by the CEA Department for Earthquake Monitoring and Prediction. An EEW test system for the BCR was established in January 2007 and was based on 16 real-time stations. The development was disrupted by the Wenchuan earthquake in 2008, after which efforts were focused on earthquake emergency-related studies and services. Since January 2010, the EEWS has been developed into a real-time system based on the Capital Circle Seismograph Network (CCSN), which consists of 162 digital telemetered seismic stations, including 94 broadband (BB) and 68 short-period (SP) stations, with an average interstation distance of approximately $50 \mathrm{~km}$. Figure $2 \mathrm{~A}$ shows the distribution of the seismic stations used for the EEWS. Each station is equipped with a three-component velocity seismom- 


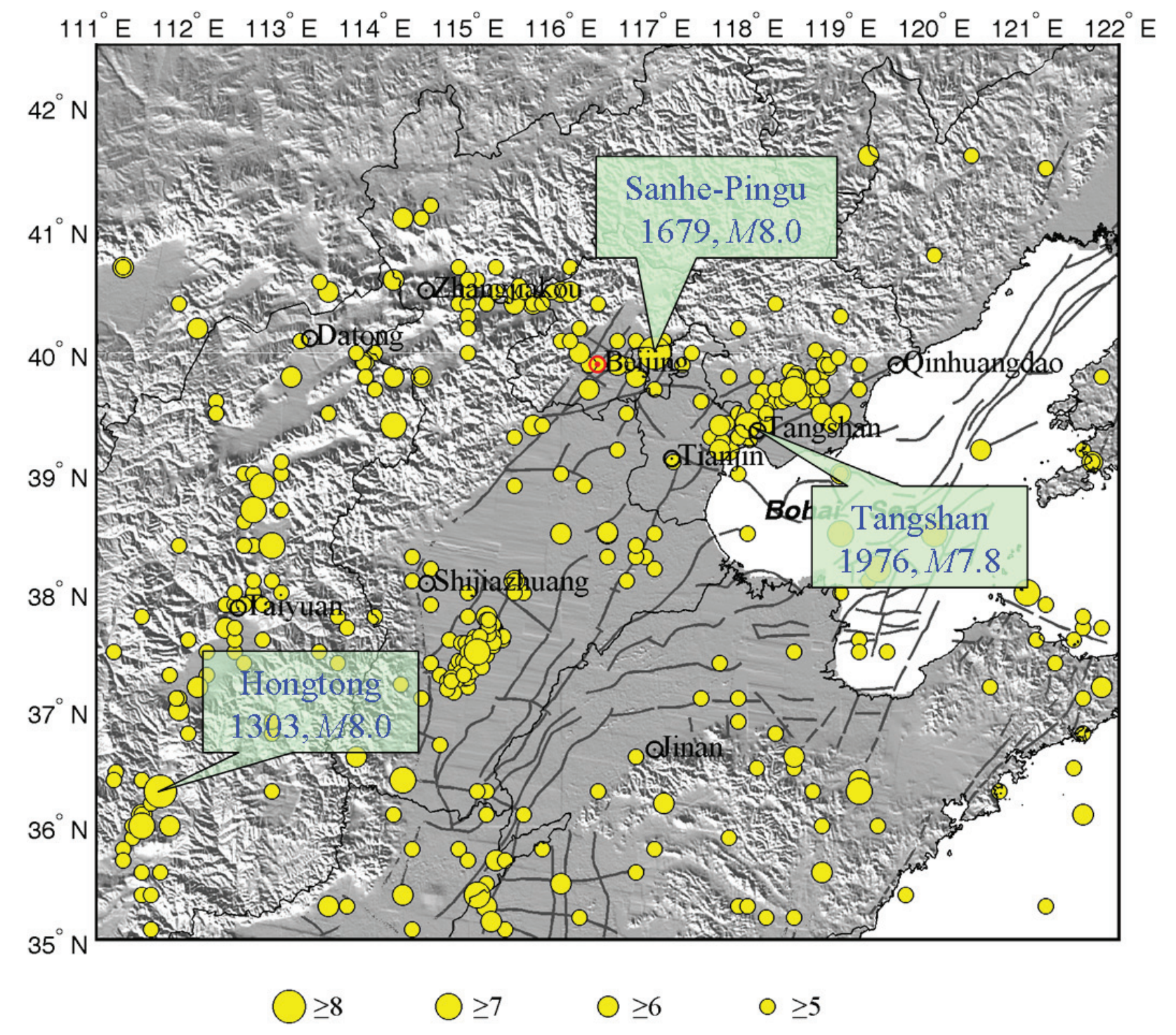

A Figure 1. Distribution of the epicenters of historical earthquakes with magnitudes greater than $\mathbf{M} 5.0$ in the BCR. Yellow dots with different sizes represent earthquakes with different magnitudes. Active faults are shown by dark gray lines. The date and magnitude of some significant earthquakes are marked on the map.

eter with 24-bit resolution (Liu et al. 2008; Zheng et al. 2010). The instruments were designed and produced by the Beijing Gangzhen (GeoDevice) Mechanical \& Electronic Technology Corporation (http://www.geodevice.cn/en/index.aspx).

Ground velocity signals are continuously transmitted to the data center of the Beijing Digital Seismograph Network (one of the four regional networks that make up the Capital Circle Seismograph Network) at a sampling rate of 100 sps. At the data center, the signals are processed by the EEW system. The initial three seconds of $P$ waves are used for magnitude determination by applying the $\tau_{c}-P d$ method (Wu and Kanamori 2005a, 2005b; Wu et al. 2007; Wu and Kanamori 2008a, 2008b; Xu et al. 2008). The hypocentral location was determined using the traditional earthquake-locating algorithm on a simplified $1-\mathrm{D}$ velocity model. Figure $2 \mathrm{~B}$ shows the configuration of the EEW system. As an example, Figures 3 and 4 illustrate the triggered waveform and the warning mes- sage for the 6 March 2010, Fengnan, Tangshan, $M_{S} 4.2$ earthquake. This earthquake was part of the aftershock sequence of the 1976 Tangshan M 7.8 earthquake. In this case, the EEWS can provide approximately 24 seconds of warning time for the center of Beijing, which is approximately $150 \mathrm{~km}$ away from the epicenter. For the EEWS in the BCR, the EEW module is automatically started when more than three stations are triggered with "reasonable" arrival time differences and interstation distances, as prescribed by the algorithm. At present, a magnitude threshold $\mathbf{M} 3.0$ has been set by the system. An automatic report of the earthquake information includes the origin time, the location and magnitude of the earthquake, the epicentral distance of the target region, and the estimated time of the peak $S$-wave arrival. The report is sent automatically through mobile phone messages and/or e-mail. Currently, as a test mode, only members of the research group and prescribed users can receive the warning information. 
(A)
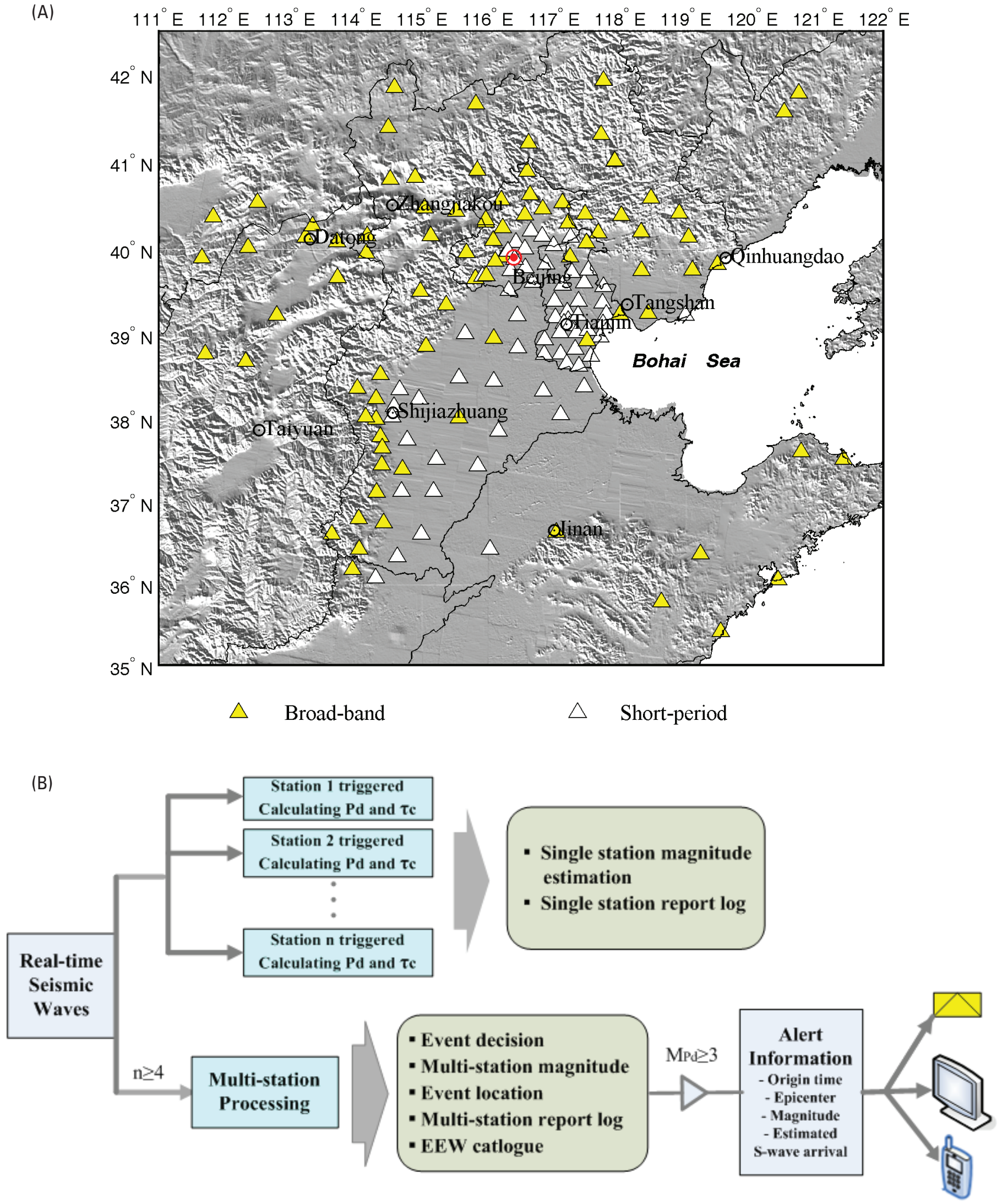

A Figure 2. A) Distribution of real-time seismic stations in the BCR used for the prototype EEW system. Yellow triangles represent the broad-band seismographs and white triangles represent the short-period seismographs. The data center is located in Beijing, as shown by the red dot. B) Configuration of the EEW system flowchart. 


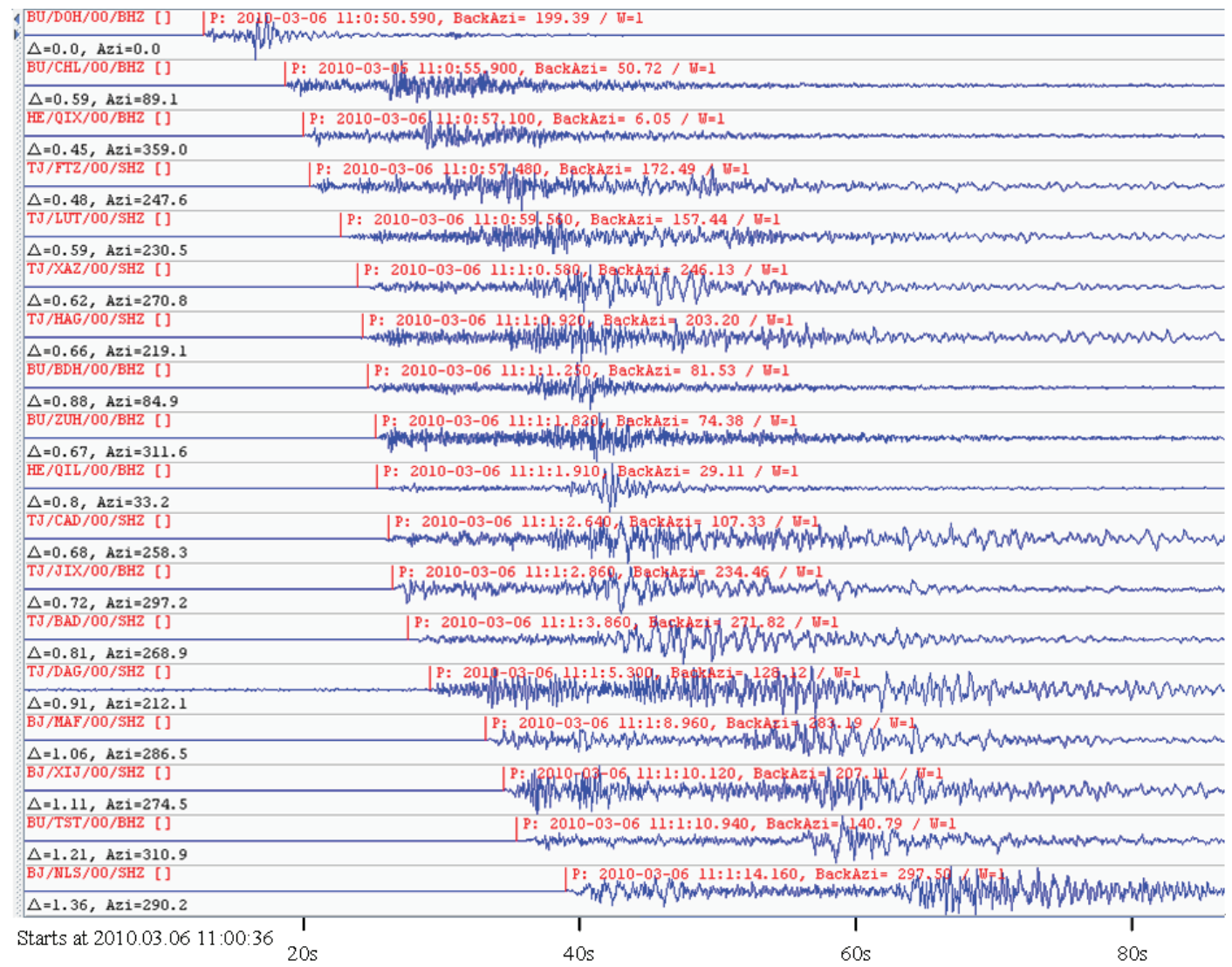

D Figure 3. Triggered waveforms of the Fengnan $M_{S} 4.2$ earthquake, which occurred on 6 March 2010. For the EEW system in the BCR, the EEW module is automatically triggered when more than three stations are triggered with "reasonable" arrival time differences and interstation distances, as prescribed by the algorithm.

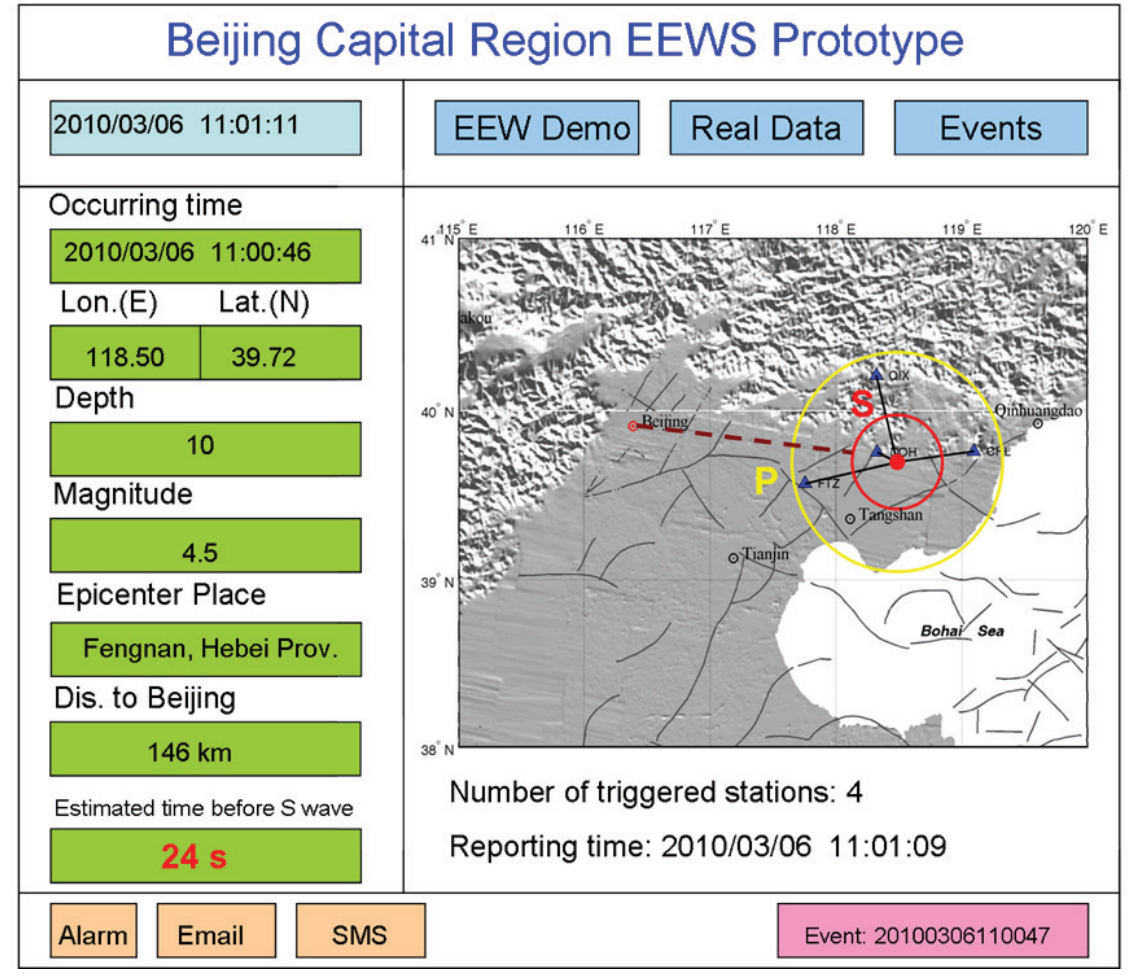

A Figure 4. Interface demo of the BCR prototype EEW system. 


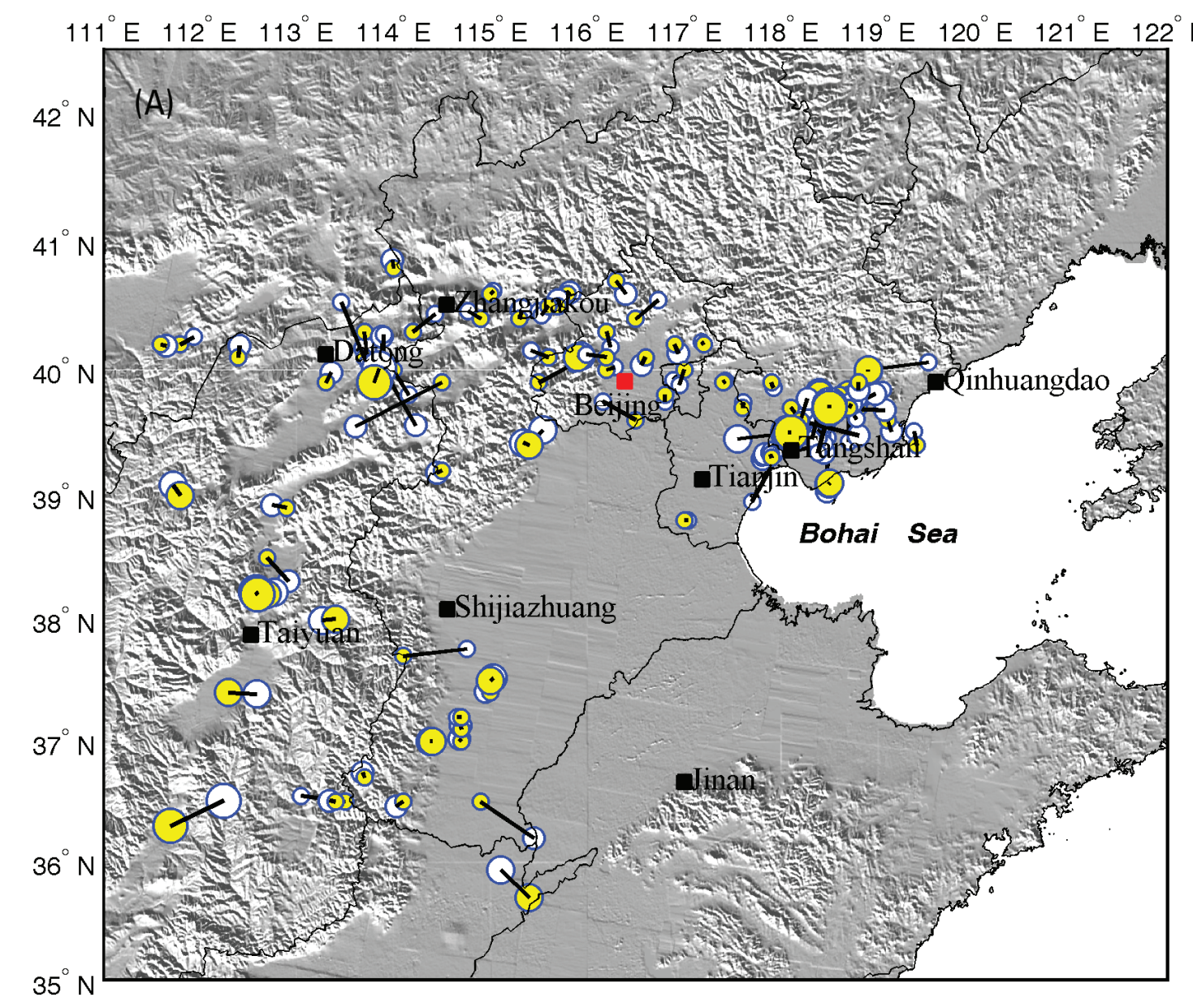
$\bigcirc \geq 4$
$\bigcirc \geq 3$
$\bigcirc \geq 2$
$0<2$
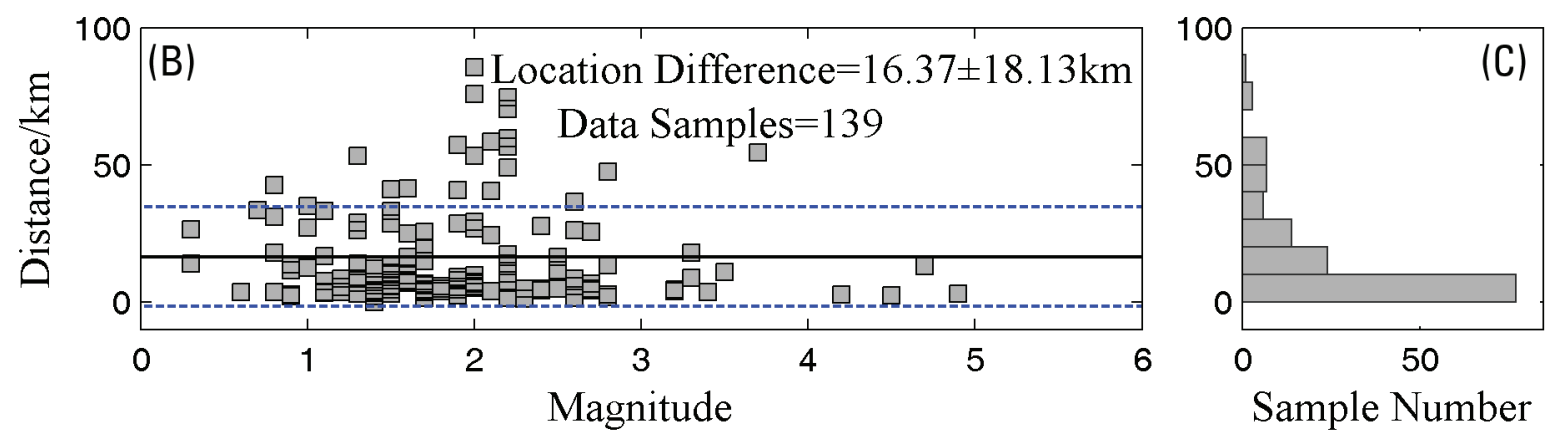

$\Delta$ Figure 5. A) Distribution of epicenters of earthquakes (natural earthquakes only) reported by the EEW system, with magnitudes from 0.3 to 4.9. Dots with different sizes represent events with different magnitudes. White dots represent the EEW report, yellow dots represent the network report (as ground-truth information of the EEW) provided by the CENC, and black line between the EEW location and the network-reported location shows the quality of the EEW location. B) Location difference between the EEW automatic locations and the CENC network locations, varying with different magnitudes. Solid line shows the average difference of the EEW automatic location with the CENC location, and the two dashed lines show the range of one standard deviation. Here the magnitude uses the EEW automatically determined magnitude $M_{P d}$. C) Histogram of the location difference for all 139 events. 


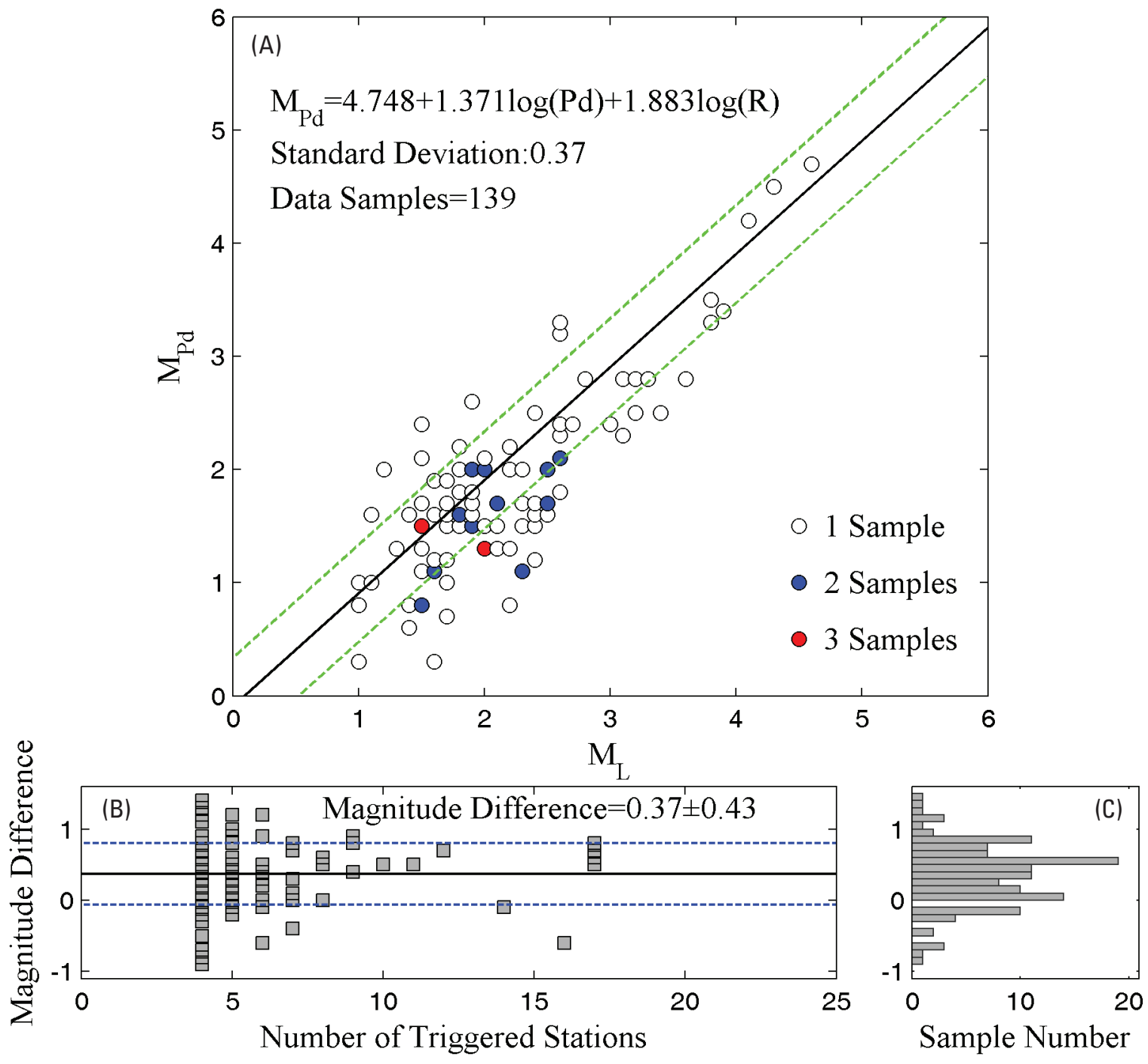

$\Delta$ Figure 6. A) The $M_{P d}$ determined automatically by the EEW system compared with the $M_{L}$ provided by the CENC. The white circle represents one event, the blue circle represents two events, and the red circle represents three events. The solid line shows the leastsquares fit, and the two dashed lines show the range of one standard deviation. B) Difference between the $M_{P d}$ determined automatically by the EEW system and the $M_{L}$ provided by the CENC, varying with different numbers of triggered stations. The solid line shows the average magnitude difference of the EEW automatic result compared with the CENC catalog, $\left(M_{L}-M_{P d}\right)$, and the two dashed lines show the range of one standard deviation. C) Histogram of the magnitude difference for all 139 reports.

\section{SYSTEM PERFORMANCE: EVENT LOCATION, MAGNITUDE ESTIMATION, AND SYSTEM RESPONSE TIME}

From 1 February 2010, to 31 August 2010, there were 215 effective EEW reports, including 139 earthquakes and 76 quarry blasts, that occurred in or near the BCR. In this study, only natural earthquakes are discussed. Figure 5A shows the epicenter distribution of the study events, with magnitudes ranging from 0.3 to 4.9. The identification and reporting of the artificial explosions, with most magnitudes less than $\mathbf{M} 3.0$, is the subject of future work. The network catalogs were provided by the China Earthquake Networks Center (CENC) and were used as ground-truth information for the EEW-determined events. Figures 5-7 show a comparison between the EEW automatic locations and the CENC network locations as well as between the $M_{P d}$ (Wu and Zhao 2006) determined automatically by the EEW system and the $M_{L}$ provided by the CENC, together with the response times.

Figure 5B presents the location differences between the EEW automatic locations and the CENC network locations, varying by magnitude. The solid line shows the average difference between the EEW automatic location and the CENC location, and the two dashed lines show one standard deviation. Figure $5 \mathrm{C}$ provides a histogram of the location differences. For all 139 events (Figure 5A), the average difference was $16 \mathrm{~km}$, with most within $10 \mathrm{~km}$. For those events greater than M 3.0, the difference was relatively smaller. The differences in the hypocentral locations between the EEW catalog and the CENC catalog are attributed primarily to the simplified 1-D 

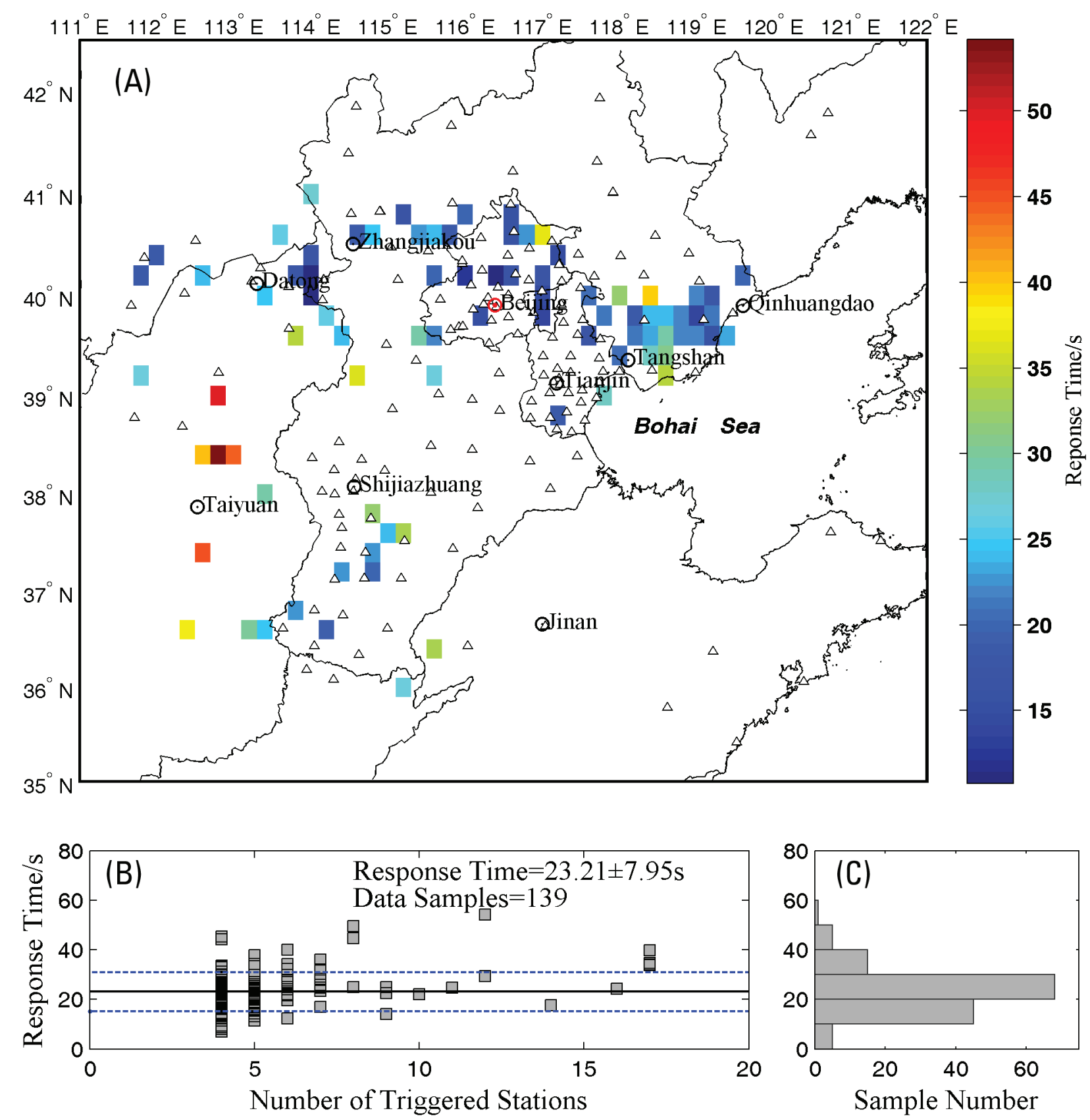

$\Delta$ Figure 7. A) Distribution of the average response time. The color of the square represents the average response time in that region with a size of $0.2^{\circ} \times 0.2^{\circ}$. The response time is measured by the duration from the origin time of the earthquake to the time for the first report to be sent from the system. The average response time is obtained with all the events reported in the same box. Triangles represent the distribution of seismic stations. B) Response time for all the events reported by the EEW system, varying with different numbers of triggered stations. The solid line shows the average response time for the 139 events, and the two dashed lines show the range of one standard deviation. C) Histogram of the response time for all 139 events.

velocity model used in the EEW location algorithm and to the station distribution in some local regions. For future development of the EEWS, an improved 1-D velocity model could be adopted, and more stations could be installed to sample more uniformly in space.

The magnitude determination using the existing $P d$ attenuation relationship with the hypocentral distance $R$ in southern California was adopted for the first stage of the EEWS
(Wu and Zhao 2006; Wu et al. 2007) and can be expressed as follows:

$$
M_{P d}=4.748+1.371 \times \log _{10}(P d)+1.883 \times \log _{10}(R) .
$$

Figure $6 \mathrm{~A}$ shows that this relation can be used in the Beijing area; however, this relation underestimates the magnitude by about 0.4 units on average. This provides an average calibration 
for the EEW magnitude estimator. For events greater than $\mathbf{M}$ 4.0 , the two types of magnitudes show relatively good coincidence. Currently, most of the seismic events are small, with a poor signal-to-noise ratio. Therefore, the $\tau_{c}$ magnitude did not perform well (Shieh et al. 2011). The Beijing Seismograph Network uses both SP and BB signals in its operation. Most of the SP stations are distributed in the platform region to the east. This may cause problems when determining the magnitude of larger events, as discussed by $\mathrm{Xu}$ et al. (2008). Figure $6 \mathrm{~B}$ shows the difference between the $M_{P d}$ estimate by the EEW system and the $M_{L}$ provided by the CENC, varying by the number of triggered stations. Figure $6 \mathrm{C}$ shows the histogram of the magnitude difference for all 139 events. For all the studied events, the average magnitude difference was approximately 0.4 magnitude units. Generally, the events with only four stations triggered had large variations in the magnitude difference. This variation was mainly caused by mislocation, which can lead to large errors in the magnitude determination. Another factor leading to the magnitude difference is the $P d$ attenuation relationship with the hypocentral distance. This relationship should be reconsidered in a future study.

Figure $7 \mathrm{~A}$ presents the distribution of the average response time. The color of the square represents the average response time in that region, with a size of $0.2^{\circ} \times 0.2^{\circ}$. The response time was measured as the duration from the occurrence of an earthquake to the time of the first report sent from the system. The average response times were obtained and reported in the same box for all events. Triangles represent the distribution of seismic stations and are deterministic factors of the response time. Figure $7 \mathrm{~B}$ shows the response times for all the natural earthquakes reported by the EEW system, varying by the number of triggered stations. The solid line shows the average response time for all 139 events, and the two dashed lines show one standard deviation. Figure $7 \mathrm{C}$ gives the histogram of the response time. At the present stage, the response times for most events are distributed from 10 seconds to 30 seconds, with an average value of 23 seconds after the origin time of an event. Therefore, the EEWS is capable of issuing a timely warning to an area located outside the epicenter by about $80 \mathrm{~km}$, before the arrival of the peak $S$ wave, with the assumption that the $S$-wave speed equals $3.5 \mathrm{~km} / \mathrm{s}$. In the near future, the response time for most events occurring in the BCR could be reduced because the present CCSN has been designed to accommodate denser stations in the coming years.

\section{DEALING WITH FALSE ALARMS: A PRACTICAL PERSPECTIVE}

The relationship between the number of triggered stations and the reporting time shown in Figure 7 is not straightforward. The distribution of seismic stations is not homogeneous, and the quality of these seismic stations is not very stable. As a result, two events with five triggered stations may have very different station spacing and, therefore, different reporting times. However, on average, the response time is approximately 23 seconds. This is still not the "earthquake early warning" we would like to achieve. Another factor contributing to the response time latency is the response time of the cell-phone communication network. However, this is much faster than the routine quick earthquake determination (QED) service of the present regional network, which generally needs several minutes according to the technical norm of the CEA.

Another problem with the prototype EEWS is its false alarm. For events greater than $\mathbf{M} 2.0$, there were 59 triggered reports during 1 February 2010 to 31 August 2010, among which 16 events were false alarms, yielding a rate of $27 \%$. For events greater than $\mathbf{M}$ 3.0, the false alarm rate can be reduced to 14\%. Among them, an "M 6.8 earthquake" reported to occur in Changli, Hebei Province, at 04:34:16 a.m. on 27 February 2010 , is the biggest false alarm. These false alarms were caused primarily by abnormal signals recorded at approximately the same time by several neighboring seismic stations.

Solving this problem in the algorithm is one of the issues for future discussion. However, countermeasures have to be considered so that these false alarms do not cause serious problems. The key issue at present is that the EEW message be used in a proper way. Currently, the EEW message is designed as an alert message and aims to catch the attention of network analysts, earthquake emergency related decision-makers within CEA, and prescribed users who use the EEW message as an alert. The role of the alert is to "trigger" these users and reduce the preparation time needed for the next step. Subsequently, a correction message is sent three minutes after the alert message. If the "first-hit" message is shown to be a false alarm, then the action of the end users is simply canceled. In the future, the messages can also be used by hospitals and schools with proper guidance. On the other hand, however, key engineering needs include a denser network, with a combination of a seismological network and a strong-motion network, careful calibration and evaluation of the system, and the necessary facilities for emergency countermeasures.

In future work, the EEWS for the BCR will be continuously updated and refined to reduce the false alarm rate. A denser seismic network will be adopted, technical methods for frequency-domain processing to recognize and discriminate abnormal signals will be used, and time-space coherence of all triggered stations will be automatically analyzed. Additionally, by increasing the triggering threshold for magnitude and number of triggered stations, the false alarm rate will be decreased.

\section{CONCLUSIONS AND DISCUSSION: EVALUATION OF THE EEWS PERFORMANCE WITH IMPLICATIONS FOR FUTURE SYSTEM OPTIMIZATION}

Compared to other regions, the BCR has special characteristics. First, seismicity is mainly composed of small earthquakes, which increases the difficulty in evaluating the EEW capability and calibrating the EEW magnitude estimator. Second, the earthquakes are distributed over a large spatial range; therefore, it is hard to differentiate front-detection and on-site EEW (consequently, it is a "hybrid-type"). Finally, the main infrastructure 
for seismological observations and strong-motion observations are just beginning to be merged; therefore, the development of an EEW system based on the seismological network still plays a key role, at least at the present stage while the two systems are still separate.

The results from this study have shown the capabilities of the prototype EEWS in the BCR on existing seismic networks. Although a majority of the reported events were small earthquakes and/or quarry blasts, using the network catalog as calibrating information we can evaluate the response time and automatic location, as well as the magnitude estimation (for the low-magnitude range). The result is of practical importance for the design and optimization of the system. In the design and optimization, one of the key factors is the number of triggered stations. As seen from Figures 5-7, the trade-off between reporting time (the speed) and location and magnitude (the quality) means that more than five triggered stations are useful for EEW operation. Minimizing false alarms and missing reports is also important. As time elapses, ongoing evaluation, calibration, and optimization of the system may make the system more reliable. This evaluation also suggests an EEW perspective for the planning and upgrading of the seismic network in the near future. $\mathbf{\Sigma}$

\section{ACKNOWLEDGMENTS}

Thanks to the BDSN for providing the infrastructure and technical assistance for the development of the prototype EEW system and to Profs. Mengtan Gao and Yanxiang Yu for stimulating discussion. Thanks to Dr. Richard Allen and Prof. Aldo Zollo for discussion of the methodology and system construction of the EEWS. This research was supported by the National Key Technologies R\&D Program of the Ministry of Science and Technology of the People's Republic of China, contribution number 2009BAK55B04. Research was also partially funded by Seismological Research Project number 20080806.

\section{REFERENCES}

Alcik, H., O. Ozel, N. Apaydin, and M. Erdik (2009). A study on warning algorithmsfor Istanbul earthquake earlywarningsystem. Geophysical Research Letters 36, L00B05; doi:10.1029/2008GL036659.

Allen, R. M., H. Brown, M. Hellweg, O. Khainovski, P. Lombard, and D. Neuhauser (2009). Real-time earthquake detection and hazard assessment by ElarmS across California. Geophysical Research Letters 36, L00B08; doi:10.1029/2008GL036766.

Allen, R. M., P. Gasparini, O. Kamigaichi, and M. Bose (2009). The status of earthquake early warning around the world: An introductory overview. Seismological Research Letters 80, 682-693.

Allen, R. M., and H. Kanamori (2003). The potential for earthquake early warning in southern California. Science 300, 786-789.

Böse, M., E. Hauksson, K. Solanki, H. Kanamori, and T. H. Heaton (2009). Real-time testing of the on-site warning algorithm in southern California and its performance during the July 29, 2008 Mw 5.4 Chino Hills earthquake. Geophysical Research Letters 36, L00B03; doi:10.1029/2008GL036366.

Böse, M., C. Ionescu, and F. Wenzel (2007). Earthquake early warning for Bucharest, Romania: Novel and revisited scaling relations. Geophysical Research Letters 34, L07302.
Böse, M., F. Wenzel, and M. Erdik (2008). PreSEIS: A neural networkbased approach to earthquake early warning for finite faults. Bulletin of the Seismological Society of America 98, 366-382.

Brown, H., R. M. Allen, and V. F. Grasso (2009). Testing ElarmS in Japan. Seismological Research Letters 80 (5), 727-739.

Cua, G., M. Fischer, T. Heaton, and S. Wiemer (2009). Real-time performance of the Virtual Seismologist earthquake early warning algorithm in southern California. Seismological Research Letters 80 (5), 740-747.

Cua, G., and T. Heaton (2007). The Virtual Seismologist (VS) method: A Bayesian approach to earthquake early warning. In Earthquake Early Warning Systems, ed. P. Gasparini, G. Manfredi, and J. Zschau, 97-132. Berlin and New York: Springer.

Erdik, M., Y. Fahjan, O. Ozel, H. Alcik, A. Mert, and M. Gul (2003). Istanbul earthquake rapid response and the early warning system. Bulletin of Earthquake Engineering 1, 157-163.

Espinosa-Aranda, J. M., A. Cuellar, A. Garcia, G. Ibarrola, R. Islas, S. Maldonado, and F. H. Rodriguez (2009). Evolution of the Mexican Seismic Alert System (SASMEX). Seismological Research Letters 80 (5), 694-706.

Espinosa-Aranda, J. M., A. Jimenez, G. Ibarrola, F. Alcantar, A. Aguilar, M. Inostroza, and S. Maldonado (1995). Mexico City Seismic Alert System. Seismological Research Letters 66, 42-52.

Fleming, K., M. Picozzi, C. Milkereit, F. Kühnlenz, B. Lichtblau, J. Fischer, C. Zulfikar, O. Ozel, and the SAFER and EDIM Working Groups (2009). The Self-organizing Seismic Early Warning Information Network (SOSEWIN). Seismological Research Letters 80 (5), 755-771.

Goltz, J. D., and P. J. Flores (1997). Real-time earthquake early warning and public policy: A report on Mexico City's Sistema de Alerta Sismica. Seismological Research Letters 68, 727-733.

Horiuchi, N. J., S. H. Negishi, K. Abe, A. Kamimura, and Y. Fujinawa (2005). An automatic processing system for broadcasting earthquake alarms. Bulletin of the Seismological Society of America 95, $708-718$.

Hoshiba, M., O. Kamigaichi, M. Saito, S. Tsukada, and N. Hamada (2008). Earthquake early warning starts nationwide in Japan. Eos, Transactions, American Geophysical Union 89, 73-80.

Hsiao, N.-C., Y.-M. Wu, T.-C. Shin, L. Zhao, and T.-L. Teng (2009). Development of earthquake early warning system in Taiwan. Geophysical Research Letters 36, L00B02.

Ionescu, C., M. Böse, F. Wenzel, A. Marmureanu, A. Grigore, and G. Marmureanu (2007). Early warning system for deep Vrancea (Romania) earthquakes. In Earthquake Early Warning Systems, ed. P. Gasparini, G. Manfredi, and J. Zschau, 343-349. Berlin and New York: Springer.

Kamigaichi, O. (2004). JMA earthquake early warning. Journal of the Japan Association for Earthquake Engineering 4, 134-137.

Kamigaichi, O., M. Saito, K. Doi, T. Matsumori, S. Tsukada, K. Takeda, T. Shimoyama, K. Nakamura, M. Kiyomoto, and Y. Watanabe (2009). Earthquake early warning in Japan: Warning the general public and future prospects. Seismological Research Letters 80 (5), $717-726$.

Kanamori, H. (2005). Real-time seismology and earthquake damage mitigation. Annual Review of Earth and Planetary Sciences 33, $195-214$.

Köhler, N., G. Cua, F. Wenzel, and M. Böse (2009). Rapid source parameter estimations of southern California earthquakes using PreSEIS. Seismological Research Letters 80 (5), 748-754.

Liu, R. F., J. C. Gao, Y. T. Chen, Z. L. Wu, Z. B. Huang, Z. G. Xu, and L. Sun (2008). Construction and development of China digital seismological observation network. Acta Seismologica Sinica 21 (5), 535-541.

Nakamura, Y. (1988). On the urgent earthquake detection and alarm system (UrEDAS). In Proceedings of the 9th World Conference on Earthquake Engineering, Tokyo-Kyoto, Japan. VII, 673-678. 
Nakamura, Y. (1996). Real-time information systems for hazards mitigation. In Proceedings of the 11th World Conference on Earthquake Engineering, Acapulco, Mexico, paper no. 2134.

Nakamura, Y. (2004). UrEDAS, urgent earthquake detection and alarm system, now and future. In Proceedings of the 13th World Conference on Earthquake Engineering Vancouver, Canada, August 2004, paper no. 908 .

Nakamura, Y., and J. Saita (2007). UrEDAS, the earthquake warning system: Today and tomorrow. In Earthquake Early Warning Systems, ed. P. Gasparini, G. Manfredi, and J. Zschau, 249-282. Berlin and New York: Springer.

Olivieri, M., R. M. Allen, and G. Wurman (2008). The potential for earthquake early warning in Italy using ElarmS. Bulletin of the Seismological Society of America 98, 495-503, doi:10.1785/0120070054.

Satriano, C., Y. -M. Wu, A. Zollo, and H. Kanamori (2011). Earthquake early warning: Concepts, methods and physical grounds. Soil Dynamics and Earthquake Engineering 31, 106-118, doi: 10.1016/j. soildyn.2010.07.007.

Shieh, J. T., Y.-M. Wu, and R. M. Allen (2008). A comparison of $\tau$ and $\tau_{p}^{\max }$ for magnitude estimation in earthquake early warning. Geophysical Research Letters 35, L20301.

Shieh, J. T., Y.-M. Wu, L. Zhao, W.-A. Chao, and C.-F. Wu (2011). An examination of $\tau_{c}-P d$ earthquake early warning method using a strong-motion building array, Soil Dynamics and Earthquake Engineering 31, 240-246, doi:10.1016/j.soildyn.2009.12.015.

Suárez, G., D. Novelo, and E. Mansilla (2009). Performance evaluation of the seismic alert system (SAS) in Mexico City: A seismological and a social perspective. Seismological Research Letters 80 (5), 707-714.

Weber, E., G. Iannaccone, A. Zollo, A. Bobbio, L. Cantore, M. Corciulo, V. Convertito, M. Di Crosta, L. Elia, A. Emolo, C. Martino, A. Romeo, and C. Satriano (2007). Development and testing of an advanced monitoring infrastructure (ISNET) for seismic early warning applications in the Campania region of southern Italy. In Earthquake Early Warning Systems, ed. P. Gasparini, G. Manfredi, and J. Zschau, 325-341. Berlin and New York: Springer.

Wenzel, F., M. Onescu, M. Baur, and F. Fiedrich (1999). An early warning system for Bucharest. Seismological Research Letters 70, 161-169.

Wu, Y.-M., and H. Kanamori (2005a). Experiment on an onsite early warning method for the Taiwan early warning system. Bulletin of the Seismological Society of America 95, 347-353.

Wu, Y.-M., and H. Kanamori (2005b). Rapid assessment of damage potential of earthquakes in Taiwan from the beginning of $P$ waves. Bulletin of the Seismological Society of America 95, 1,181-1,185.

Wu, Y.-M., and H. Kanamori (2008a). Development of an earthquake early warning system using real-time strong motion signals. Sensors $8,1-9$.

Wu, Y. -M., and H. Kanamori (2008b). Exploring the feasibility of onsite earthquake early warning using close-in records of the 2007 Noto Hanto earthquake. Earth, Planets, Space 60, 155-160.
Wu, Y.-M., H. Kanamori, R. Allen, and E. Hauksson (2007). Determination of earthquake early warning parameters, $\tau_{c}$ and $P d$, for southern California. Geophysical Journal International 170, 711-717.

Wu, Y.-M., and T.-L. Teng (2002). A virtual subnetwork approach to earthquake early warning. Bulletin of the Seismological Society of America 92, 2,008-2,018.

Wu Y.-M., H.-Y. Yen, L. Zhao, B.-S. Huan, and W.-T. Liang (2006). Magnitude determination using initial $P$ waves: A singlestation approach. Geophysical Research Letters 33, L05306; doi:10.1029/2005GL025395.

Wu, Y.-M., and L.Zhao (2006). Magnitude estimation using the first three seconds $P$-wave amplitude in earthquake early warning. Geophysical Research Letters 33, L16312, doi:10.1029/2006GL026871.

Wurman, G., R. M. Allen, and P. Lombard (2007). Toward earthquake early warning in northern California. Journal of Geophysical Research 112, B08311; doi:10.1029/2006JB004830.

Xu, Y., Z. L. Wu, C. S. Jiang, Y. X. Yu, and J. S. Yang (2008). Estimating the size of an earthquake using short-period seismograms of the first three seconds: A simulated experiment using the 1999 Jiji (Chi-Chi) earthquake sequence. Acta Seismologica Sinica 21 (2), 139-147.

Yamada, M., and T. Heaton (2008). Real-time estimation of fault rupture extent using envelopes of acceleration. Bulletin of the Seismological Society of America 98, 607-619.

Yamada, M., T. Heaton, and J. Beck (2007). Real-time estimation of fault rupture extent using near-source versus far-source classification. Bulletin of the Seismological Society of America 97, 1, 890-1,910.

Zheng, X. F., Z. X. Yao, J. H. Liang, and J. Zheng (2010). The role played and opportunities provided by IGP DMC of China National Seismic Network in Wenchuan earthquake disaster relief and researches. Bulletin of the Seismological Society of America 100 (5B), 2,866-2,872, doi: 10.1785/0120090257.

Zollo, A., G. Iannaccone, M. Lancieri, L. Cantore, V. Convertito, A. Emolo, G. Festa, F. Gallovic, M. Vassallo, C. Martino, C. Satriano, and P. Gasparini (2009). Earthquake early warning system in southern Italy: Methodologies and performance evaluation. Geophysical Research Letters 36, L00B07.

Zollo, A., M. Lancieri, and S. Nielsen (2006). Earthquake magnitude estimation from peak amplitudes of very early seismic signals on strong motion records. Geophysical Research Letters 33, L23312.

\section{Institute of Geophysics China Earthquake Administration Beijing 100081 penghs@cea-igp.ac.cn} (H.P.) 